\title{
Determination of the region of the limiting states occurrence in RVS-20000 with the subsidence of the external bottom contour
}

\author{
P.V. Chepur ${ }^{1}$, A.A. Tarasenko ${ }^{1}$, and A.A. Gruchenkova ${ }^{2,}{ }^{*}$ \\ ${ }^{1}$ Industrial University of Tyumen, 625000 Volodarskogo Street 38, Russia \\ ${ }^{2}$ Surgut Oil and Gas Institute, 628405 Entuziastov Street 38, Russia
}

\begin{abstract}
The problem of the limiting states occurrence in the structures of a vertical steel tank is investigated in this work. To study the SSS of the metal structures of the object, the authors created a numerical model of the RVS-20000 tank in the ANSYS software complex. The model considers the maximum number of elements with their geometry and connections affecting the tank SSS under non-axisymmetric loading, including beyond the elasticity of steel. Dependences between the parameters of intrinsic stiffness of the VST are obtained. The results of the finite element analysis made it possible to develop a technique for assessing the technical condition of the structure with the development of irregular subsidence of the external bottom contour. The proposed technique can be used by both operating and design organizations in making managerial decisions regarding the repair of RVS-20000 subjected to the base subsidence.
\end{abstract}

\section{Introduction}

Calculation of the vertical steel tank (VST) structures should be performed according to the method of limiting states of the first and second groups in accordance with [1]. We understand limiting states as those in which the bearing structures of the VST cease to meet the specified operational requirements or requirements for the performance of work. During the construction and operation of large tanks, loads and impacts arise which, under certain conditions, can cause the emergence of limiting states of both the first (loss of bearing capacity and total inoperability of structures) and the second group (hindering of the normal operation of the VST) [2, 3].

Modern regulatory documents [1-3] regulate verification calculations for determining the value of the limiting states of the first and second groups. To do this, the limiting states of the first group are checked by calculating the maximum loads and the effects possible in case of a violation of normal operation, and the limiting states of the second group are tested for loads corresponding to the normal operation of the structures. Even though these basic documents consider the main loads (hydrostatic, snow, wind, weight of equipment, overpressure and vacuum, etc.), an idealized case is calculated, which does not reflect the geometric imperfections of the form during construction, deviation of the base marks from

* Corresponding author: alesya2010-11@yandex.ru 
the design due to possible defects of CIWs, etc. These factors, according to [4-9], affect the total SSS of the tank and, ultimately, the occurrence of limit states.

Irregular subsidence of the external bottom contour is one of the most dangerous factors due to which the limiting state of one of the groups may occur [10]. After the first 5 years of operation, in almost $25 \%$ of cases, according to [11, 12], deviations of the external bottom contour from the design value occur. In this case, a relatively safe uniform subsidence of the VST along the contour due to compaction of the soil massif and the appearance of unevenness along the external bottom contour may occur, which, during development, can lead to plastic deformations of the metal and further destruction.

If the uneven tank subsidence exceeds the allowable value by the normative document $[3,13]$, the method of repair is severely regulated - the method of lifting the tank with the help of jacks is used (Figure 1). However, this does not consider the history of loading the VST over the entire life cycle, the nature of uneven subsidence $[14,15,16]$.

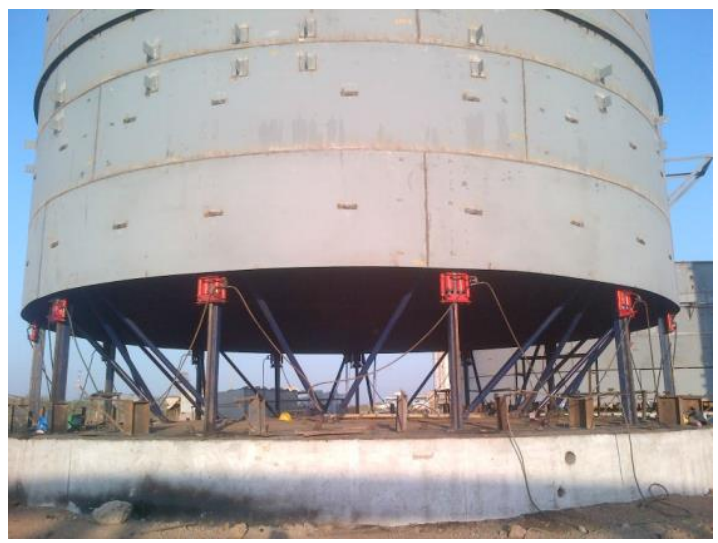

Fig. 1. The method of lifting the vertical steel tank with the help of jacks is used.

So, uneven subsidence can inherently result from defective construction and installation works, design errors, and can appear under the action of cyclic operational loads. Proceeding from this, it is necessary to consider the level of initial stresses in the VST structures when justifying repairs in order to avoid the appearance of plastic deformations during lifting [17-18].

\section{Methods}

To study the limiting deformation values of RVS-20000, the authors created a numerical model in the finite element software complex ANSYS [19-21]. Verified in [22], the RVS20000 model allowed determining the parameters of the tank's intrinsic stiffness for various values of uneven subsidence.

The dimensionless parameter $\mathrm{m}$ used in the theory of shells was used to determine the size of the uneven subsidence zone, and the parameter $\mathrm{S}$ was used to specify the values of the vertical displacements of the uneven subsidence. The RVS-20000 model proposed by the authors in a non-axisymmetric setting according to the standard design considers all operational loads: hydrostatic, wind, snow, excess and vacuum pressure, etc. The contact problem of the interaction of the ground base and the reinforced concrete foundation ring was solved. The model considers the work of the main structural elements of the VST: wall, annular plate, support stiffening ring, roof beams, sheet roofing, foundation ring. The junction of the wall, the annular plate and the foundation ring is modeled considering the results obtained in [14]. 


\section{Results and discussion}

The research carried out by the authors made it possible to develop an engineering technique for determining the need for repairing RVS-20000 at base subsidence. In Figure 2 , based on the results of calculations, interpretation and analysis of the data on the intrinsic stiffness of the tank, a scheme is given for estimating the actual technical condition of the structure with uneven subsidence.

According to the available data from the report on tank diagnostics - the intersection point of the $m$ warp curve (calculated depending on the radius of the VST and the length of the subsidence zone) and the vertical component of subsidence $\mathrm{S}$, it is possible to determine the "danger zones".

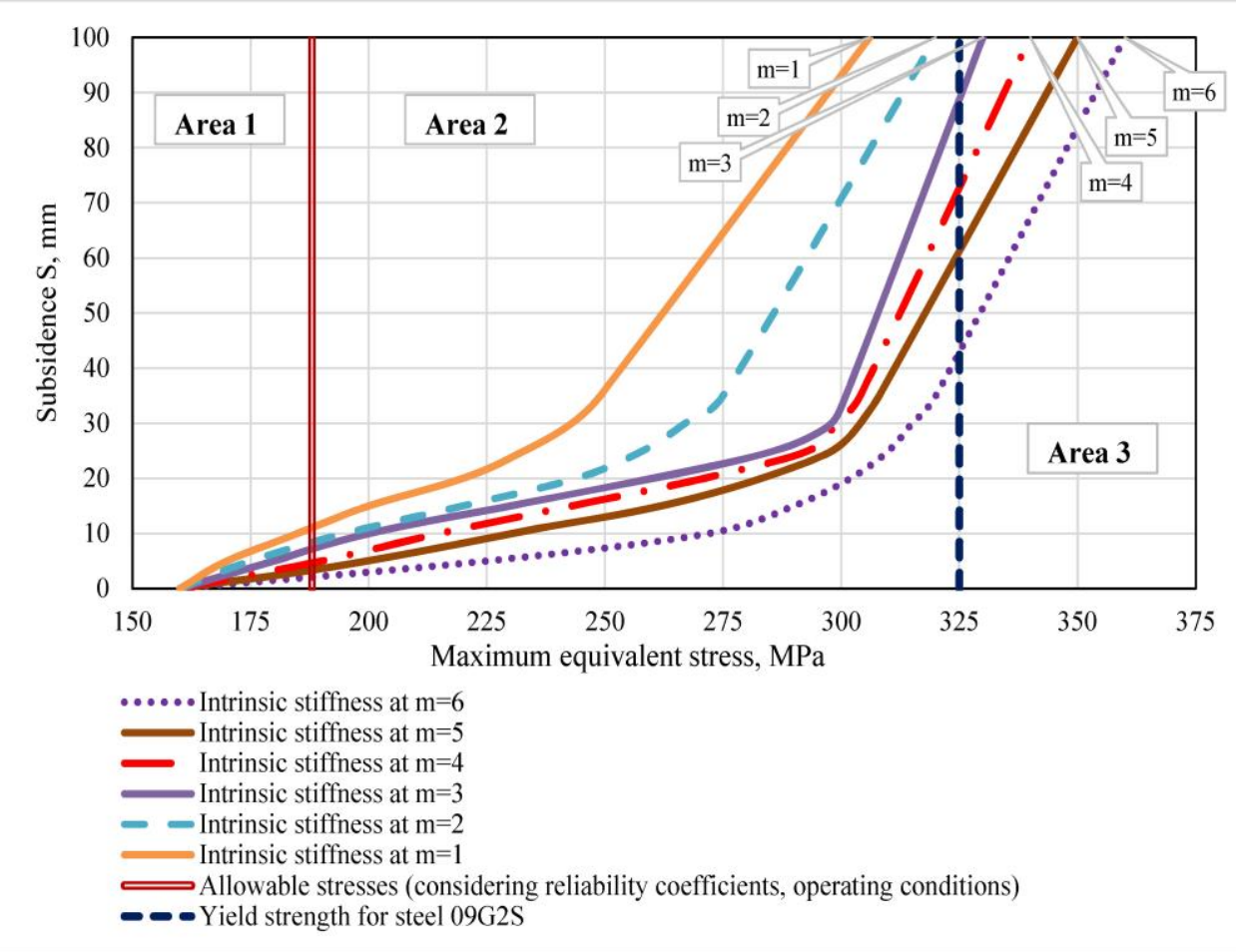

Fig. 2. Graph for determining the occurrence of limit states in the metal structures of the tank.

The first danger area determines the level of the tank SSS at which the effective stresses do not exceed those permitted by the regulatory documents $[1,2]$ and constitute $[\sigma]=188$ $\mathrm{MPa}$. It is guaranteed that within the limits of this zone the limiting state of neither the first nor the second group can occur. The second danger area is limited by the yield point of the tank steel 09G2S $[\sigma]=325 \mathrm{MPa}$. Under certain conditions, the emergence of limiting states of the second group in the VST structures is possible in this zone; repair is necessary to avoid further development of the level of stresses and deformations. The entry of the point of intersection of the straight $\mathrm{S}$ and the curve $\mathrm{m}$ into the third danger area indicates that in the tank there may be limiting states of both the I and II groups, the VST in this case is in emergency condition and immediate repair work is required.

In the complex analysis of the SSS of the RVS-20000 structures, the authors identified the most vulnerable zones manifested at the non-axisymmetric loading which is caused by uneven subsidence. At a subsidence value $m \leq 3$, zones of increased stresses appear in the wall above the "fracture" line, which is geometrically a chord passing through the 
boundaries of the warp zone. Figure 3 shows a diagram with the distribution of equivalent stresses in a given node.

Analyzing the deflections of the shell structure of the wall at irregular subsidence, sometimes reaching $30 \mathrm{~cm}$ in the radial direction above the subsidence zone, the question arises of ensuring the stability of a thin cylindrical shell - the wall of the tank. This area deserves detailed research.

When studying the distribution of stresses in the structures, it was found that for $m \leq 5$, significant stresses are concentrated at the junction of the roof, wall and support ring. Of particular interest is the fact that the greatest stresses in this junction do not arise in the stiffening ring, but in the section of the wall sheet of the 8th belt over the stiffening ring. This indicates the need to introduce additional requirements for monitoring the continuity of the welded joints of the support ring and the wall as part of a diagnostic survey when uneven subsidence is detected.
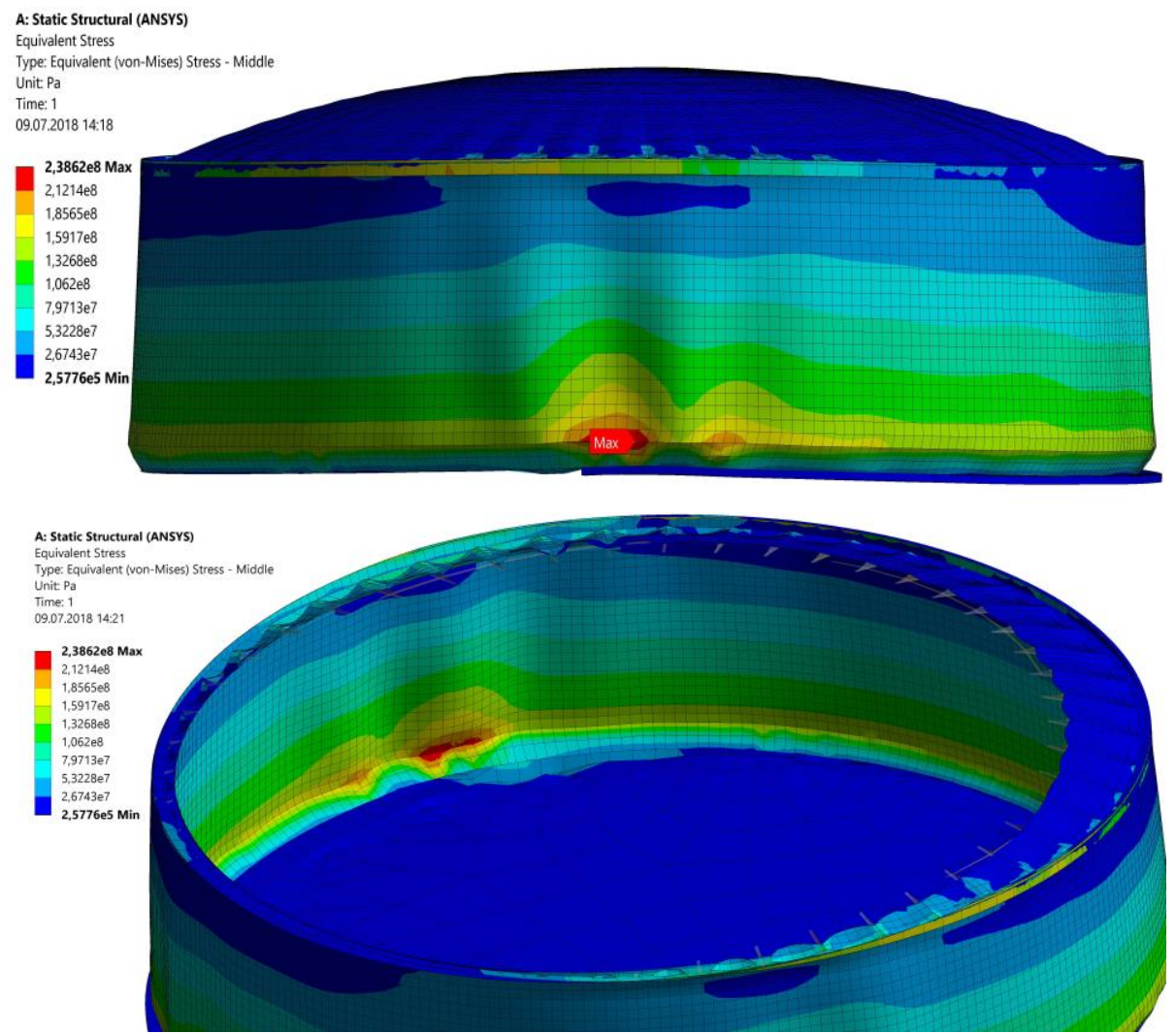

Fig. 3. Effective stresses in the wall of the RVS-20000 tank.

Considering the influence of uneven subsidence on the tank SSS, the appearance of significant deflections of the roof beams in the axial direction was discovered. When operating a real object, this can lead to a rupture of the welded joint of the roofing sheets and, as a consequence, to the depressurization of the gas space of the VST. The nature of deformation of the beam framework of the roof is in the form of half-waves, the number of which is determined by the intrinsic stiffness of the VST and the parameters of the subsidence zone. Figure 4 shows an illustration with deflections of the roof framework of the VST with non-uniform subsidence at the size of the subsidence zone $\mathrm{m}=1$ (the scale of deformations is increased 50 times for visualization). 


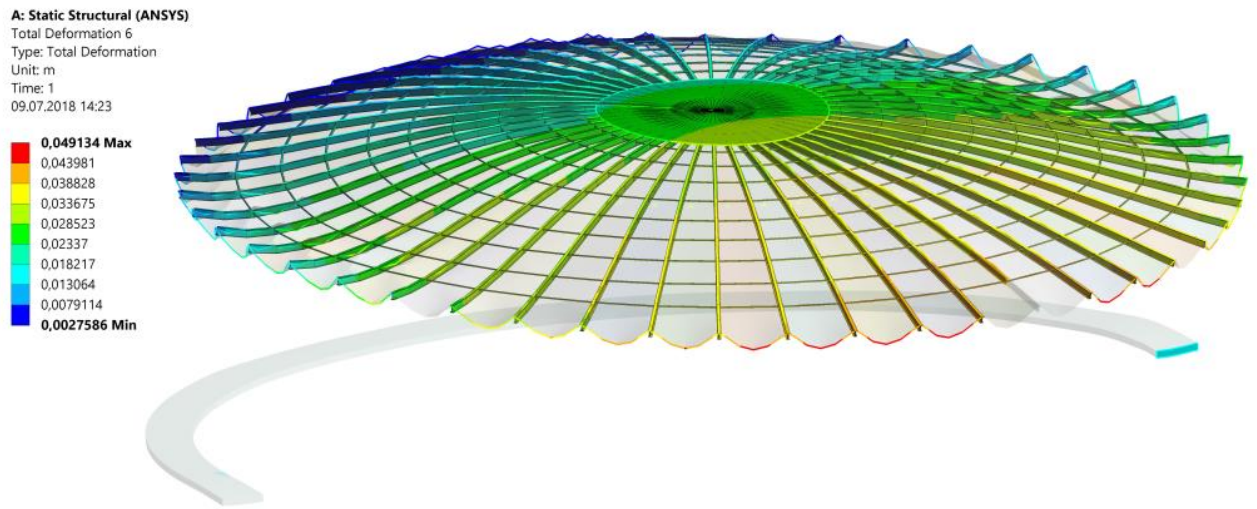

Fig. 4. Deflections of the beam framework of the roof of the RVS-20000 tank at subsidence $m=1$.

\section{Conclusions}

The authors created a numerical model of the RVS-20000 tank, considering the maximum number of elements of the metal structures, taking into account their geometry and connections affecting the tank SSS under non-axisymmetric loading, including beyond the elasticity of steel. Dependences have been obtained between the parameters of the SSS and the value of uneven subsidence $S$ for the subsidence zones of various sizes. The obtained parameters of intrinsic stiffness of RVS-20000 made it possible to develop a technique for assessing the technical condition of the structure when uneven subsidence of the external bottom contour develops. Dependences of the effective stresses in the VST structures on the values of $\mathrm{m}$ and $\mathrm{S}$ are obtained, and areas of the limiting states are determined in accordance with which a decision is made on the need for repair or the possibility of continuing the operation of the tank subject to technical justification.

\section{Acknowledgments}

The paper was prepared within the implementation of the basic part of the government task for the project № 7.7858.2017/BP: "Development of the scientific principles of the techniques for determining the stress-strain state of the large-sized storage tanks during the differential settlement of the substructures and foundations".

\section{References}

1. Russian State Standard GOST 31385-2016

2. Russian State Standard GOST R 52910-2008

3. Russian State Standard RD-23.020.00-KTN-283-09

4. S. Chirkov, A. Tarasenko, P. Chepur, IOP Conf. Series: Earth and Environ. Sci. 90, 012102 (2017)

5. A.A. Tarasenko, P.A. Konovalov, F.F. Zekhniev, P.V. Chepur, D.A. Tarasenko, Soil Mech. and Found. Eng. 53(6), 405-411 (2017)

6. A. Tarasenko, P. Chepur, A. Gruchenkova, AIP Conf. Proc. 1772, 060011 (2016) 
7. A.A. Tarasenko, P.V. Chepur, A.A. Gruchenkova, J. of Phys.: Conf. Series 1015, 032047 (2018)

8. A.A. Tarasenko, P.V. Chepur, S.V. Chirkov, Oil Indust. 3, 123-125 (2016)

9. Y. Guan, A.A. Tarsenko, S. Huang, P.V. Chepur, R. Zhang, World Inf. on Earthquake Eng. 32(1), 219-227 (2016)

10. A.A. Tarasenko, P.V. Chepur, Soil Mech. and Found. Eng. 53(4), 238-243 (2016)

11. A.S. Gorelov, Neodnorodnye gruntovye osnovaniya $i$ ikh vliyanie na rabotu vertikal'nykh stal'nykh rezervuarov (Nedra, Saint Petersburg, 2009)

12. A.A. Tarasenko, P.V. Chepur, S.V. Chirkov, D.A. Tarasenko, Fundam. Res. 10(15), 3404-3408 (2013)

13. RD-23.020.00-KTN-271-10, Pravila tekhnicheskoy diagnostiki rezervuarov (OAO AK "Transneft", Moscow, 2010)

14. A. Gruchenkova, A. Tarasenko, P. Chepur, D. Tarasenko, AIP Conf. Proc. 1800, 040019 (2017)

15. A. Tarasenko, P. Chepur, A. Gruchenkova, MATEC Web of Conf. 73, 01018 (2016)

16. A. Tarasenko, P. Chepur, S. Chirkov, AIP Conf. Proc. 1772, 060010 (2016)

17. A.A. Tarasenko, A.A. Gruchenkova, M.A. Tarasenko, Oil Indust. 8, 132-135 (2016)

18. A. Tarasenko, A. Gruchenkova, P. Chepur, Proc. Eng. 165, 1125-1131 (2016)

19. A.V. Beloborodov, Vestnik of the Ural Fed. Univ. 1, 78-81 (2005)

20. V.A. Bruyaka, V.G. Fokin, E.A. Soldusova, N.A. Glazunova, I.E. Adeyanov, Inzhenernyy analiz v ANSYS Workbench (Samara state technical University, Samara, 2010)

21. G.E. Korobkov, R.M. Zaripov, I.A. Shammazov, Chislennoe modelirovanie napryazhenno-deformirovannogo sostoyaniya $i$ ustoychivosti truboprovodov $i$ rezervuarov v oslozhnennykh usloviyakh ekspluatatsii (Nedra, Saint Petersburg, 2009)

22. A.A. Tarasenko, P.V. Chepur, Y. Guan, Oil Indust. 4, 134-136 (2016) 